\title{
Design Sequence Experiences: A Panel Discussion
}

\author{
Ron Britton University of Manitoba, ron_britton@umanitoba.ca \\ François Charron, University of Sherbrooke, Francois.R.Charron@USherbrooke.ca \\ Trevor Dickinson, University of Guelph,wdickins@uoguelph.ca \\ Pat Little, Harvey Mudd College, patrick little@hmc.edu \\ Warren Stiver, University of Guelph,wstiver@uoguelph.ca
}

\begin{abstract}
A number of engineering schools choose to deliver their design engineering education through a coordinated sequence of courses. There are a number of advantages to this approach but also many challenges. This session, in panel discussion format, will share experiences, challenges, successes and vision of design sequence education from the perspectives of a number experienced practitioners.
\end{abstract}

\section{Introduction.}

Engineering design is the essential ingredient of engineering practice. Engineering schools deliver design education in a diverse manner. A number of schools have developed a sequence of design courses in their efforts to graduate a design competent engineer.

Harvey Mudd College started a Design Clinic, in 1963. Today, they continue to run a sequence of five required courses culminating in a clinic that serves all of their engineering students. University of Manitoba have run a design trilogy in their Biosystems Engineering program for many years. For the past few years, Manitoba has been developing an engineers-in-residence program to bring industry expertise into the trilogy and other courses. University of Sherbrooke introduced an integrated sequence of design courses to their Mechanical Engineering program in the early 1990's. The University of Guelph has run a design sequence of four courses since the early 1970's.

This paper shares some of the thoughts and experiences of four design educators that have been working with design sequences for a number of years. The panel discussion will start from these perspectives and move on to a lively discussion.

\section{University of Manitoba.}

One of the basic concepts upon which the Design Engineering Chair at the University of Manitoba was founded was the belief that there was a need to expand student access to persons with design experience. Existing academic staff, for the most part, have built their careers around $\mathrm{PhD}$ studies and research experience. Those with actual design experience were, and are, the exception. Clearly there was a need to complement the skills and experience of the academic staff.

Prior to the introduction of the Design Engineering Chair it had become obvious that engineering students did not obtain all of the appropriate skills within their academic studies to be able to transition smoothly into the commercial world. For the most part the curriculum focused on developing specific competencies with specific analysis and design tools using constrained problems. Little time was spent on open ended, multiple solution problems that required the integration of the technical skills developed in other courses. As a result, industry had observed that it took them an inordinate amount of time and effort to provide the graduates with basic skills appropriate to their particular industry. While there were some capstone design courses in which students undertook design projects in response to industry problems and programs, the industry contact was minimal and standard industry practices were not necessarily followed. Industry had requested that a theme be introduced into the engineering academic curriculum whereby students are taught industry skills in the context of their academic studies.

Although this issue was understood, there was no room in the curriculum and limited expertise in the faculty to implement such an idea. It fell, therefore, to the Design Chair to introduce first year courses that introduced industry design skills such as teamwork, problem solving, and communication skills. Also, the capstone design projects were expanded and made more relevant. 
The ability to deliver these courses was constrained by the human resources available on campus.

In the summer of 2001, using funds generated by the Design Engineering Chair, the first Engineers-inResidence were appointed. This unique type of appointment was developed as a part of the effort to better understand the form and function of the design process and how this process is taught within the engineering curricula in Canada and, especially, at the University of Manitoba.

Engineers-in-Residence positions require persons with backgrounds in as design engineers in industry or government rather than traditional academic qualifications. The initial idea was to draw these persons from among the ranks of recently retired engineers and, therefore, the positions were created as part-time positions. As the concept developed, a second source of engineers emerged from among small independent consultants. This later group brought current industry involvement to complement their past experience.

Today there are six Engineers-in-Residence covering all of the engineering programs at the University of Manitoba. Typically, they have between 25 and 35 years of industry design experience, four of the six are retired and all spend at least $50 \%$ of their time "in residence" on the campus. In this way they can be counted on to be directly (face-to-face) available to the students for the above activities.

Responsibilities of the individual Engineers-inResidence vary depending on their backgrounds and the "culture" of the department they interact with. In general, however, they are asked to provide industry practice input to relevant courses, teach courses in industry practice, mentor students in team design projects, provide Faculty Advisor duties to student societies such as SAE, CASI, CSME, IEEE, etc., and aid in introducing the professional engineering societies to students. Their contacts beyond the campus have facilitated the development of new relationships with companies who have not, in the past, seen value in direct involvement with the university.

Engineers-in-Residence complement, but do not replace traditional academic staff. For the most part they work with professorial staff to expand their courses beyond the academic and embrace the industrial. With three years of experience in this program, the Engineers-inResidence have become more and more integrated into the programs and are being considered by all academic staff as being reliable, available, and useful resources for their courses. The students have come to realize the value of the knowledge resident in these engineers and also they are very appreciative of the industry contacts that the Engineers-in-Residence bring to the campus.

\section{$3 \quad$ University of Sherbrooke.}

After completing a pilot project in design engineering education between 1992 and 1994 and conducting an exhaustive literature review about mechanical engineering education [1], the Mechanical Engineering Department at Sherbrooke University decided to develop and implement a major reform of its undergraduate program [2]. The two principal cornerstones of this reform were:
- a program based on the development of competencies (technical and professional);
- a program combining engineering sciences and engineering design through integration projects carried out during the first four terms and a major design project carried out during the four last terms.

The following sections present the various elements involved in the major design project done in the last four terms of the undergraduate mechanical engineering program at Sherbrooke University.

\subsection{Design Sequence}

In the four first terms, the students are doing four integration projects (one project per term) introducing them to engineering design. These integration projects are open-ended design problems allowing the students integrating the various subjects cover in a given term. The Design Sequence at Sherbrooke is considered the design activities completed in the last four terms. The principal items in each of these terms is summarize in Table 1.

\section{Table 1 - Sherbrooke design activities}

\begin{tabular}{|l|l|l|l|}
\hline $\begin{array}{l}\text { Semester 5 } \\
\text { (S5) }\end{array}$ & Semester 6 & Semester 7 & Semester 8 \\
\hline $\begin{array}{l}\text { Design } \\
\text { Methodology }\end{array}$ & $\begin{array}{l}\text { Design } \\
\text { Project I }\end{array}$ & $\begin{array}{l}\text { Design } \\
\text { Project II }\end{array}$ & $\begin{array}{l}\text { Design } \\
\text { Project III }\end{array}$ \\
\hline
\end{tabular}

The main activities completed in each of these terms are:

- S5: Project definition, team selection, feasibility study, etc.; Design methodology includes product development process (PDP), design process and various PDP and design tools (e.g. functional analysis, QFD, etc.).

- S6: Market definition, need definition, functional analysis, specification document, generation 
and selection of concepts.

-S7: $\quad$ Preliminary design including all the necessary engineering analysis for the definition of the optimal dimensioning

-S8: $\quad$ Detailed design, fabrication and assembly of the prototype and experimental validation

Two very important and fairly unique activities of the design projects are the project selection in S5 and the final exhibition at the end of S8. The following sections will discuss more specifically about each of them.

\subsection{Design project definition}

Teams are formed and design projects selected in the fifth term (S5), which is one term before the beginning of the design project courses (I to III). From the very start of the term, projects suggested by companies (external industrial partners) are presented to the students.

As the result of repeated discussions between students over eight weeks and a student presentation given at around mid-term, each team submits a proposal slightly before the end of term including a project description, a team composition, a technological pre-feasibility study, and a preliminary budget with the potential sources of funding [3]. With this document, professors review the proposals, provide final comments to the students before the end of the fifth term and accept or not the proposed project.

\subsection{Design project exhibition}

It was apparent to us from the outset that building a complete functional prototype would be a key element of this new vision of teaching engineering design. However, the design and building of a product, system, or machine will always involve a number of uncertainties, which justified the fact that the objective would not always be achieved if the students were not ready to intensify their efforts to deal with certain exceptional situations.

After reflection, we felt that the best means for ensuring that the students would achieve the goal was to have them exhibit their projects. It should be kept in mind that students are like all designers: they are proud of their projects and have a very strong sense of team belonging. An exhibit is a simple way to strike this sensitive cord.

Moreover, the exhibit also offers an opportunity to present four posters about the project. These posters present the design process used by the students during the four terms (duration of 24 to 28 months) and show the obtained results (e.g. needs, functions, concepts, calculations and simulations, etc.) including a presentation of the prototype. Lastly, the exhibit can also be a catalyst in stimulating the development of new partnerships with companies and to show to the community the student's accomplishments.

\subsection{Examples of design projects}

Table 2 presents a list of projects recently done by the students at Sherbrooke University in the Mechanical Engineering Department.

\section{Table 2 - Previous Sherbrooke designs}

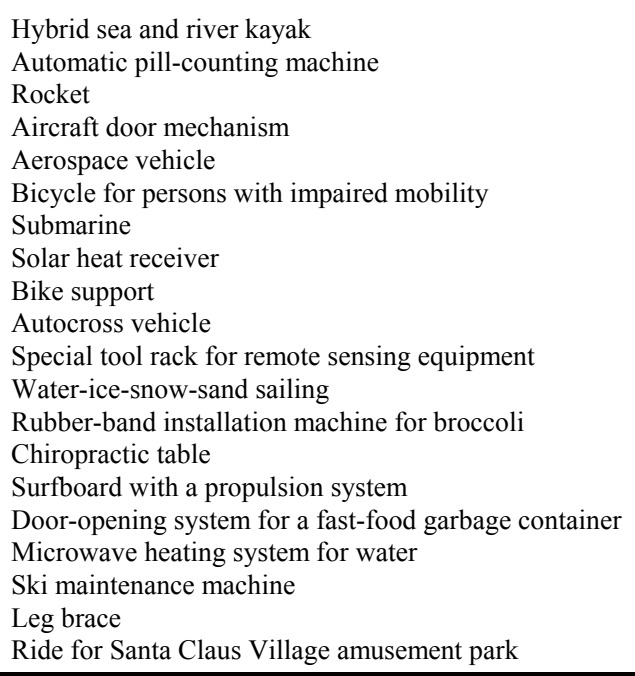

The great diversity in projects should be readily evident. This can be explained by the fact that the definition of design projects rests mainly on the personal interests of the students and the opportunities offered by the companies from a variety of economic sectors.

Finally, Figure 1 provides a mosaic of pictures of some design projects exhibited in December 2000. Prototype quality is obvious.

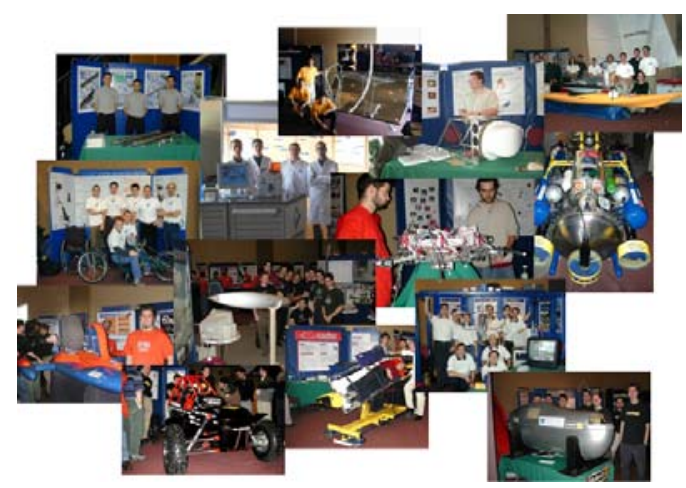

Figure 1. Sherbrooke design mosaic 


\section{$4 \quad$ University of Guelph.}

\subsection{The Concept}

Guelph's engineering program instituted a sequence of design courses starting in 1973. The original vision involved four design courses, one course in each year of the program. These four courses were seen to form the "trunk" of the engineering program. The basic mathematics and science courses, engineering science courses and electives formed the branches, grounded by the trunk but also feeding into it.

The first year course was intended to "shore up" fundamental analytical and drafting/drawing skills, as well as offer students an opportunity to explore what engineers do. The analytical portion has included components dealing with mathematical fundamentals, a probabilistic perspective, notions of accuracy and precision, linear and nonlinear scales, and notions of steady and unsteady states etc. Teams of students also went into the community to interview practicing engineers and shared oral reports regarding their findings back in the classroom.

The second year course has focused on the design process, affording students opportunities to learn about and practice components of the process (e.g. preparing problem statements, and constraints and criteria), and prepare a proposal for and undertake a design project.

Students completed three mini-design projects in the third year course. Each project had its roots within a specific engineering discipline (e.g. water resources engineering, food engineering), requiring each student to undertake work in a range of disciplines. The projects incorporated and wove together material and skills from the earlier design and other courses taken previously by the students.

The fourth year course provided a capstone design opportunity. Faculty identified suitable projects, while some students brought forward their own candidate projects, many of the projects being linked to current problems.

The original vision underlying this sequence of four design courses recognized three characteristics to be key. The first was that design was central to the engineering program, and that the design sequence therefore served as the "trunk" or core of the program. The second characteristic was the importance of team skills, both for all students involved and for all faculty delivering the program. Third was the importance of communication skills, both written and oral. A sequence of four design courses continues to be central to the engineering program at Guelph, thirty years after the original concept and vision was developed.

\subsection{Some of the Challenges \\ Design as the Trunk}

The vision behind the design sequence forming the trunk of the engineering program at Guelph saw these courses clarifying the rationale and need for all the other courses, and saw how material and skills presented in these course "branches" could feed the engineering design process and program. Needless to say, such a vision relies on an incredible level of team work among faculty delivering the program. While engineering faculty have generally recognized the importance of their students learning good team skills, they often prefer to develop and deliver their courses with considerable independence. Also the engineering program, including the design sequence, has obviously involved a great many faculty members over its thirty year history. As a result, it has remained an ongoing challenge to maintain the continuity required to achieve the vision.

The continuity addressed here involves a number of dimensions. There are the key characteristics of the program i.e. the trunk, team skills etc. Have these remained key? Should they? Then there is the sequence of four design courses. Has their content changed? Should it? How? Do they continue to flow and feed into one another? And then there is the matter of maintaining linkages between the engineering "branch" courses and the trunk. Have such linkages indeed been maintained? Or have many of the courses become "suckers"?

The original trunk vision has been somewhat lost at times over the years, with connections among engineering science and engineering design courses becoming fragile if not broken. Indeed, the trunk/tree may have become closer to a shrub with "suckers", offering the students a package of 40 or so more or less independent and disconnected courses. Following such intervals, efforts have been undertaken to restore the tree structure. For example, the focus of the Engineering Analysis (Matrix Algebra) course was shifted from being solely on techniques for solving systems of equations and matrices to a problem context, requiring students to derive equations in light of particular problems. Another example is the manner in which improved linkages have been made between the second year design course and the materials course. Students are now required to give more consideration to material properties etc. as they work on their design projects. And so attempts continue to reestablish and maintain a tree structure.

It is acknowledged that although maintaining some level of continuity in the dimensions noted above seems very 
important, choosing rigidity with little or no flexibility is not desirable. So the challenge has been to maintain a appropriate level of ongoing dialogue amongst all faculty involved to insure the health and growth of this engineering design tree.

\section{Team skills}

Skills associated with team work were a central part of the original vision, and team projects and team activities have become the norm throughout the sequence of design courses and in some other engineering courses. The size of teams has varied considerably over the years, often being linked to class size and resources. Providing the students with many team based projects is one important dimension associated with team skills. A second dimension is to help students understand normal team dynamics and the impact which their differing preferred learning styles have on these dynamics. This perspective has been a consistent component of the second year design class.

Single discipline, cross-discipline and multi-discipline teams have all been part of the sequence over time. The first and second year design courses have consistently been cross-discipline in their team work. This is somewhat easier to maintain based on the common or nearly common curriculum of all of the students up to the completion of the second design course. The third year design course has shifted over time from an initial domain of cross-discipline to a single discipline over the past ten years or more. The capstone design course also flirted with multi-disciplinary projects a number of years ago. However, the effort never gained any momentum.

Individual as opposed to team projects were instituted for a few years in the final capstone design course. Such a "mutation" in the tree has often been triggered at Guelph by a change in the faculty member running one of the courses. The mutation may or may not survive that instructor; and in the case of individual design projects in the fourth year, they did not resonate in general with faculty and were discontinued. Nonetheless, it is important that changes such as this be suggested, debated and tried form time to time to permit evolution of the sequence.

\section{Communication skills}

It goes without saying that graduates of an engineering program must have good oral and written communication skills. Communication skills have therefore been a very important element in the Guelph program since its inception..

Written communication takes many forms. Engineering drawing is one such form and has always been a central part of the first year design course. Drawing skills have evolved during the thirty years of the program from the world of drafting tables to the world of computer aided drawing (CAD).

Design proposals and design reports have also been a significant part of the program, with the focus shifting over the years. There have been periods in which all four courses "covered" this domain, at times leading students to criticize the sequence as being too repetitive. Currently, the third year course is the place where particular attention is paid to the preparation of professional written reports.

Oral communication opportunities are available throughout the sequence and have always been a key element. The novel communication experience of interviewing practicing engineers, once a part of the first design course, is no longer included. The second year design course has a significant focus on oral communication, with the students preparing six presentations of varying character, including a couple of team presentations, a couple of individual presentations, an oral interview and an individual demonstration. The fourth year capstone design project requires a team poster presentation The poster session is held in the open courtyard of the University Centre, affording an opportunity for the students to experience a diverse audience, including design evaluation teams; and providing a "showcase" of the design projects for the university community.

\section{Need for Evaluation}

The program has remained professionally accredited, even though it could be said the concept and merits of having a central design core have never been fully evaluated. Certainly ongoing feedback from alumni and employers has remained extremely positive and supportive of moving and continuing to develop the program in such a direction. Nonetheless, a rather rigourous evaluation of this and similar programs might be extremely worthwhile.

\section{$5 \quad$ Harvey Mudd College.}

Harvey Mudd College (HMC) was founded approximately 50 years ago as a "liberal arts college of engineering and science". Since that time, the faculty have chosen to follow their own way in preparing students to be practicing engineers. HMC, for example, offers an unspecialized engineering major, choosing to focus on the elements that all engineers have in common while giving students a sufficient skill set to practice in any of the traditional disciplines. All students in the college (including non-engineers) take a common core 
consisting of 4 semesters of mathematics, three semesters of physics, two semesters of chemistry, and one semester each of biology, computer science, and systems engineering. All students also take at least 12 courses in humanities and social sciences. Engineering majors take the Common Core even further by continuing with a suite of 14 common courses in the major, along with three engineering electives. With such a "lockstep" approach, we are able to insure that all our students are prepared for practice, but we are also obligated to keep each course current and integrated into the larger framework. The unifying theme for our program is our belief that design is the defining aspect of engineering practice. In addition, the faculty have always been committed to the notion of a practiceoriented program. Approximately $55 \%$ of our students go immediately to professional practice, often with large organizations such as national defense or manufacturing firms. Another $35 \%$ continue on with graduate studies in engineering. Of the students who take the EIT/FE exams, we have had a remarkable success rate - in the 8 years I have been at HMC, no engineer has failed the exam. This section reviews the HMC curriculum, with a focus on how we integrate engineering education to support design.

\subsection{The Three Stems Approach}

HMC uses what has been called a "cornerstone and capstone" approach. The cornerstone is the first course in engineering, E4, Introduction to Engineering Design. The capstone is our three-semester experience, Engineering Clinic. Each of these courses is discussed below. Of more immediate interest is how we structure the curriculum to allow students to mature and improve their knowledge and skills over the four years. Coursework is based on a "three stem approach" - the Systems stem, the Engineering Science stem, and the Design and Professional Practice stem. Each stem, or leg, is intended to provide fundamental knowledge and experiences that support the practice of engineering. Together, they give the student sufficient knowledge and skills to be able to begin engineering practice and to continue with life-long learning.

The Systems stem consists of three courses in systems engineering - E59, E101, E102. The first of these, E59, Introduction to Systems Engineering, is a college-wide requirement in which students discover systems by means of signals. (The course also includes some lumped-element modeling.) Typically taken in the first semester of the sophomore year, the students are presumed to be competent in mathematics and physics. The course includes programming in MATLAB, sampling and aliasing, and other aspects of basic systems course. E101 and E102, Advanced Systems Engineering, are more advanced signal processing and controls courses, including Fourier and z-transforms, system characterization, and control theory. A common theme throughout the System stem is that the same basic approach to thinking can be applied to all engineered systems - mechanical, electrical, thermal, etc. Examples from the various domains are used interchangeably.

The Engineering Science stem consists of five required courses - Chemical Engineering, Electrical Engineering, Computer Engineering, Continuum Mechanics, and Materials Engineering. These courses can be taken in any sequence except Materials, which is generally taken last, and which calls upon subject matter from the other courses. Some of these courses tie together material from several traditional domains (e.g., continuum mechanics includes some fluids), while others, such as Electrical Engineering follow more or less standard curricula. Students often sequence these courses to allow themselves to begin more advanced electives during their Junior year. (Students take at least three upper-division electives).

The Design and Professional Practice stem consists of E4, Introduction to Engineering Design, E8, Design Representation and Realization, E80, Experimental Engineering, and Engineering Clinic, a three- semester capstone experience. E4, Introduction to Engineering Design, is the first engineering course that students take. It is often taken by non-engineers as well. It is a studiobased course in which students learn elements of engineering design and problem solving, team dynamics, oral and written communication, and simple aspects of project management. The course consists of three exercises - a relatively simple and controlled design problem (e.g., constructing a timer using materials available on a deserted island), a reverse engineering problem (e.g., functional analysis of an electric toothbrush), and a major project for a non-profit organization (e.g., design and development for UCIrvine's Surgical Devices Laboratory). As part of their design work, students make 2 oral presentations, and write a technical memorandum and a final report. E8, Design Representation and Realization, is a course in geometric design and tolerancing. In addition to standard GD\&T, students must build a tool tray, hammer and screwdriver to meet specifications. E80, Experimental Engineering, is a second year course in which student teams conduct a variety of laboratory and field experiments, including design of analog and digital filters, static and dynamic beam characterization, and design of a fluid-based torsional system. The culmination of this course is the "field experience", in which teams of students instrument a highway bridge with accelerometers and characterize the bridge in terms 
of frequency response. During E80, the students use programs that are provided by the teaching team to analyze their results. The students save and use data from this experiment in E101 and E102, when they must write their own code for frequency analysis. In addition to lab notebooks, students write a technical memorandum on the torsional system and make oral presentations on the bridge data. The final element of the Design stem is Engineering Clinic.

\subsection{Engineering Clinic at Harvey Mudd}

Engineering Clinic is the capstone set of three courses and is also the gem of the engineering education at Harvey Mudd. Clinics are 9 month (one academic year), industrially sponsored projects. Clinic teams consist of 4-5 students and a faculty advisor, working on a project posed by an industrial liaison, who also serves as the technical expert for the project team. The problems are typically very challenging, open-ended, and are of sufficient importance to the sponsors to justify the $\$$ US40,000 fee. Teams work under substantial time pressure, and are expected to meet deadlines that are set at the beginning of the project. The final product of the project is typically a documented design, a working prototype, and a written report. All the intellectual property of the project belongs to the sponsor. (This year, 3 of the 24 projects have resulted in preliminary disclosures as a first step to filing patents.) Table 3 identifies some typical projects over the years.

\section{Table 3. Previous Harvey Mudd designs}

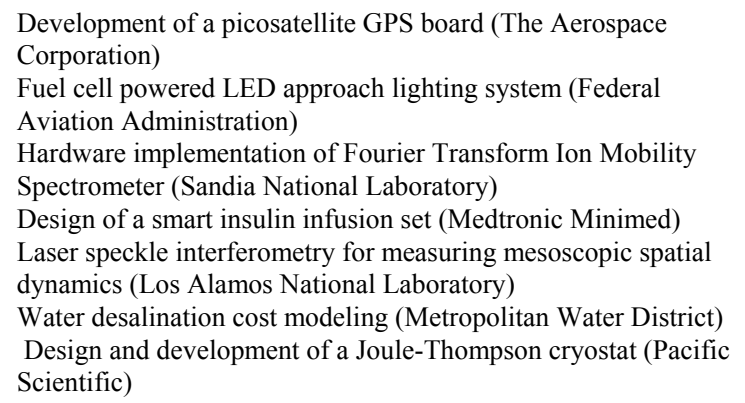

Each year, we are faced with the challenge of finding 2025 projects that meet the interests of our students and the demands of our program. Our best projects usually include a design-build-test sequence, and often span the traditional engineering disciplines. In this regard, the three stem curricular approach to engineering proves quite valuable. Most of these projects require students to work in more than one domain, and to think about design in a systematic way, not only in the sense of applying logic, but also in terms of systems engineering. Our challenge in the coming years will continue to be to shape and modify our curriculum to support a practiceoriented program for designing engineers.

\section{Summary.}

Design sequences offer a unique and cohesive means to deliver engineering design education. It is evident that different models are possible and that each of these models bring with them advantages and challenges. It is expected that the panel discussion will permit a free exchange of ideas around this style of design education. This exchange of ideas will assist in the evolution of existing programs and potentially spur additional schools to consider this format.

\section{$7 \quad$ References.}

[1] UdeS (1994), Document de travail en vue d'une réforme du programme de baccalauréat de génie mécanique: Problématique, pertinence, état des connaissances et solution proposée. Département de génie mécanique, Université de Sherbrooke, April 6, 1994, $80 \mathrm{p}$.

[2] Proulx, D., Brouillette, M., Charron, F., Nicolas, Jean. (1998), A New Competency-Based Program for Mechanical Engineers. CSME Forum - Symposium on Future Direction in Engineering Education and Profession, 1998, Toronto, Ontario, Canada.

[3] Doucet, P., Van Hoenacker, Y (2001). Picking Projects and Dealing with Time Constraints: A Learning Experience for Both Students and Faculty. 2001 Canadian Conference on Engineering Education Program (C2E2), August 22-25, 2001, University of Victoria, Victoria, British Columbia, Canada. 